\title{
MODELING PROTECTIVE DEVICES FOR DISTRIBUTION SYSTEMS WITH DISTRIBUTED GENERATION USING AN EMTP-TYPE TOOL
}

\section{REPRESENTACIÓN EN EMTP DE DISPOSITIVOS DE PROTECCIÓN DE REDES DE DISTRIBUCIÓN CON GENERACIÓN DISTRIBUIDA}

\author{
Juan A. Martínez-Velasco ${ }^{1} \quad$ Jacinto Martín-Arnedo $^{2} \quad$ Ferley Castro-Aranda $^{3}$ \\ Recibido 2 de marzo de 2010, aceptado 12 de agosto de 2010 \\ Received: March 2, 2010 Accepted: August 12, 2010
}

\begin{abstract}
RESUMEN
Este artículo presenta las características principales de una librería de módulos desarrollada para representar dispositivos de protección de una red de distribución de energía eléctrica con generación distribuida (GD). El impacto de la generación distribuida depende, entre otros aspectos, del diseño del sistema de protección y de la coordinación entre los diferentes dispositivos de protección. La presencia de unidades generadoras altera el flujo radial inherente a un sistema de distribución y afecta al comportamiento del sistema de protección. Este trabajo presenta una introducción de los sistemas de protección de las redes de distribución y de la interconexión de unidades generadoras, describe la implantación de dispositivos de protección (interruptores, relés, reenganchadores, fusibles, seccionalizadores) en un programa tipo EMTP, y presenta algunos resultados obtenidos mediante simulación, cuyo principal objetivo es ilustrar el impacto que la generación distribuida basada en generadores síncronos puede tener sobre la coordinación de los distintos dispositivos de protección.
\end{abstract}

Palabras clave: Distribución de energía eléctrica, modelación, simulación, generación distribuida, fusible, interruptor automático, relé de sobrecorriente, reenganchador, seccionalizador, protección de la conexión, funcionamiento en isla.

\begin{abstract}
This paper presents the main features of a library of modules for representation of protective devices of distribution networks with distributed generation $(D G)$. The impact of distributed generation in a distribution network depends, among other aspects, on the design of the protection system and the coordination between the different protective devices. The presence of distributed generation changes the radial nature of distribution systems and affects the performance of the protection system. This document discusses the present protection practices for distribution systems and DG interties, describes the implementation of protective devices (circuit breakers, relays, reclosers, fuses, sectionalizers) in an EMTP-type tool, and presents some simulation results whose main goal is to analyze the impact of synchronous machine-based embedded generators on the coordination between the different types of protective devices.
\end{abstract}

Keywords: Power distribution, modeling, simulation, distributed generation, fuse, circuit breaker, overcurrent relay, recloser, sectionalizer, interconnection protection, islanding.

\section{INTRODUCTION}

Distribution-level protection is based on a time-overcurrent design. Such design includes selection of equipment and settings, placement of equipment, and coordination of devices to clear faults with as little impact on customers as possible. One of the main priorities is to prevent further damage to utility equipment. Secondary goals are reliability and power quality. Distribution protection is not designed to have backup, although there must be overlap between protective devices: an upstream device should operate for a fault if the downstream protector fails. In addition, distribution protection is based on standardized settings, equipment, and procedures [1-3].

It is commonly accepted that the installation of small distributed generation (DG) units at distribution levels has many advantages: economical (energy efficiency), environmental (reduction of greenhouse gas emissions), and technical (voltage support) [4-6]. Although costs

\footnotetext{
1 Departament d'Engyniería Elèctrica, Universitat Politècnica de Catalunya. Av. Diagonal 647, CP 08028. Barcelona, España. E-mail: martinez@ee.upc.edu

2 Departamento de Distribución, ITC2. Barcelona, España. E-mail: jacinto.martin@rflor.itc2.com

3 GRALTA- Escuela de Ingeniería Eléctrica y Electrónica. Universidad del Valle. Calle 13 No 100-00. Cali, Colombia. E-mail: ferley@ieee.org
} 
associated with DG technologies are still high, DG can be a solution for those situations in which high power supply reliability is needed, or when the construction of transmission lines and large power plants is not supported by end-users.

Utilities are generally concerned that the installation of small DG units may result in damage to their equipment or to the equipment of their customers. The connection of DG units raises new challenges $[7,8]$, being islanding one of the main concerns [8-13]. Although DG may successfully operate in island if there is a balance between load and generation, islanded operation is not generally allowed for some major reasons [10-12]:

1. The utility needs to restore the outaged circuits and this is complicated by having islanded generators with utility loads. Since automatic reclosing is generally used to restore power to customers, having islanded generators complicates both automatic and manual switching, which requires synchronizing the generator/ load islanded to the utility system.

2. Power quality generally cannot be maintained by the islanded generators within an acceptable level, and this can result in damage to the customer equipment.

3. Personnel security is another reason, since maintenance and reparation crews may think that there is no voltage when in fact some generation is still active and running in islanded mode.

The impact of DG on the power quality of a distribution system is significantly affected by the design of the distribution system protection and the protection of DG interconnection. This paper summarizes the main features of a library of modules developed for representing distribution feeder and DG interconnection protective devices, and implemented in an EMTP-type tool. EMTP is an acronym that stands for Electro-Magnetic Transients Program. EMTP-type tools are circuit-oriented timedomain simulation tools presently used in a wide range of power system studies $[14,15]$. The present work has been carried out with the ATP (Alternative Transients Program) version of the EMTP [16].

This paper has been organized as follows. Next section summarizes the type of protective devices that has to be installed in a distribution system with embedded generation. The subsequent two sections describe the characteristics of distribution feeder protection and DG interconnection protection, respectively. The main core of the paper are the sections dedicated to detail the features of the EMTP models developed for this work and to analyze some test cases aimed at illustrating the impact that distributed generators can have on distribution protection.

\section{PROTECTION OF DISTRIBUTION SYSTEMS WITH DISTRIBUTED GENERATION}

This section discusses the types of devices that are used to protect distribution feeders and the requirements for the connection of small DG units to distribution feeders.

\section{Distribution Feeder Protection}

The distribution system is in general radial in design, and the distribution protection is basically overcurrent protection. Although this protection type is simple and works very well with radial networks, it possesses several characteristics that have to be accounted for when selecting the appropriate protective devices [1-3]:

- Any distribution protective device has an associated maximum distance (also known as reach) for which the device works. For large distribution networks, in which the longest distance from a load node to the substation can be several dozens of kilometers, it is impossible to protect the whole network from the substation. Therefore, several protective devices have to be installed along the network.

- A highly reliable performance of a distribution network can be achieved by installing different types of protective devices. The coordination between protective devices is another important aspect, and this is particularly difficult in distribution networks given the number of different protective devices (breaker-relay sets, reclosers, fuses, sectionalizers). This coordination is not easy and not always possible. In addition, it can be altered by the presence of distributed generators $[7,8,17]$.

- There are some transients, such as transformer inrush and cold load pickup, which can appear during system energization. The currents associated to these transients can be of the same order that the pickup current of many distribution protective devices. This aspect has to be considered when selecting the time-current characteristic of those devices that can be affected.

\section{Interconnection and Generator Protection}

Small DG units that operate interconnected with the utility distribution system can be classified into three groups: synchronous generators (recuperating engines, combustion turbines, small hydro), induction generators (wind generators) and non traditional asynchronous generators (fuel cells, photovoltaic) [10-12].

Synchronous generators have a dc field winding to provide machine excitation. They can inject both watts and VArs 
to the utility system, and require synchronizing equipment to be paralleled with the utility. Induction generators are similar to induction motors and are started like a motor (no synchronizing equipment needed). They are less costly than synchronous generators and can supply real power to the utility but require a source of reactive power, which in some cases is provided by the utility system. Most nontraditional small DG units are asynchronously connected to the power system through static power converters, which are solid-state microprocessor-controlled devices that convert $\mathrm{AC}$ voltage at one frequency to $50 / 60 \mathrm{~Hz}$ system voltage. The electronic control of the converter regulates the power output and shuts down the machine when the utility system is unavailable. The need for independent protection to avoid system islanding has not yet been determined.

Interconnection protection provides the protection that allows DG units to operate in parallel with the utility grid. Small DG units (5 MW or smaller) are usually connected to distribution systems, which are designed to supply radial load. Protection requirements to connect a small DG unit to the distribution utility grid are established by each individual utility. Large generators are reviewed on a case-by-case basis; they are usually connected to the utility's transmission system and do not employ specific interconnection protection because they are integrated into the utility protection system itself.

Properly designed interconnection protection should address the concerns of both the DG owner and the utility. Interconnection protection for small generators is established at the point of common coupling (PCC) between the utility and the DG. This point can be at the primary of the interconnection transformer as illustrated in Figure 1a, or at the secondary of the transformer as illustrated in Figure 1b, depending on ownership and utility interconnect requirements. Interconnection protection satisfies the utility's requirements to allow the DG to be connected to the grid. Its function is threefold [10-12]:

1. Disconnects the DG when it is no longer operating in parallel with the utility system.

2. Protects the utility system from damage caused by connection of the DG, including the fault current supplied by the DG for utility system faults and transient overvoltages.

3. Protects the generator from damage from the utility system, especially through automatic reclosing.

Generator protection is typically connected at the terminals of the generator, as shown in Figure 2, and provides detection of internal short circuits and abnormal operating conditions (loss-of-field, reverse power, overexcitation and unbalanced currents).

For smaller generating units, utilities usually leave the responsibility to the DG owners to select the level of generator protection they believe is appropriate. Utilities, however, become very involved in specifying interconnect protection. Typically, the following interconnection areas are specified by many utilities: winding configuration of the interconnection transformer, general requirements of "utility-grade" interconnection relays, CT and VT requirements, functional protection requirements, settings of some interconnection functions, speed of operation required to disconnect the DG prior to utility system automatic reclosing.

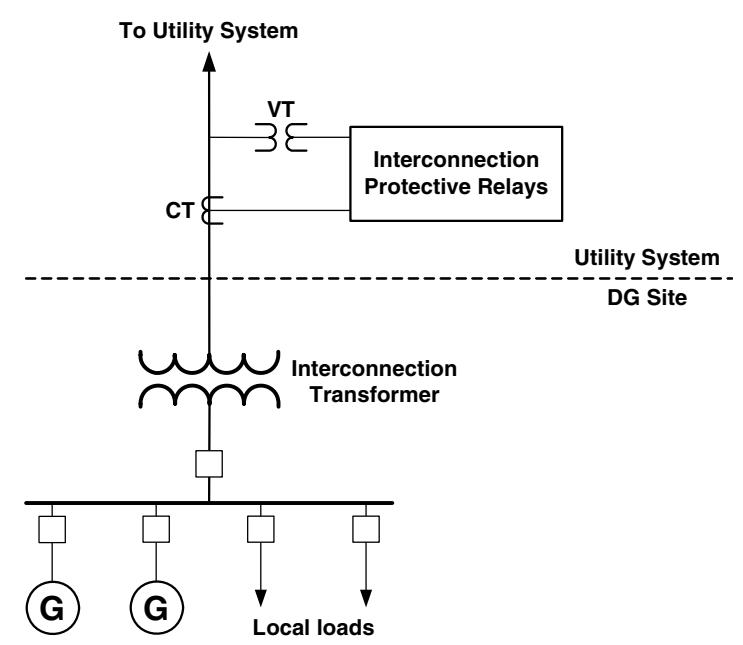

a) Protection at the transformer primary.

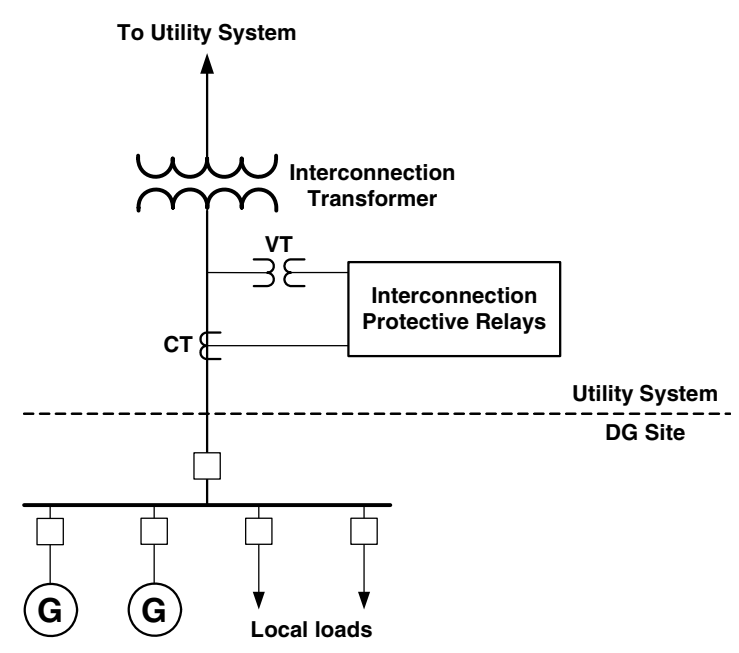

b) Protection at the transformer secondary.

Figure 1. Interconnection protection. 


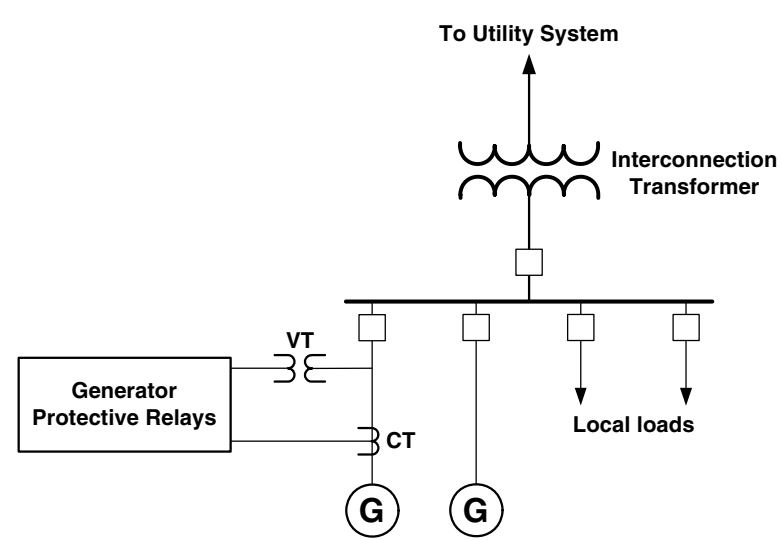

Figure 2. Distributed generator protection.

This paper analyzes the impact of small DG units based on synchronous generators only. On the other hand, since only faults originated in the distribution system are considered, only the design of interconnection protection will have an impact on the performance of the distribution system. Therefore, only the model of the interconnection protection is analyzed.

\section{DISTRIBUTION FEEDER PROTECTIVE DEVICES}

This section presents a summary of the main characteristics of protective devices presently used by utilities to protect radial distribution systems. Readers are referred to textbooks and standards for more details on overcurrent protection in distribution networks [1-3, 18, 19].

\section{Circuit Breakers - Overcurrent Relays}

A circuit breaker is an automatic interrupting device which is capable of breaking and reclosing a circuit under all possible conditions. Accurate modeling of circuit breakers is difficult due to the complexity of physical phenomena during breaking operations and the great variety of circuit breakers (oil, air, $\mathrm{SF}_{6}$, vacuum) [20].

The performance of a breaker during an opening operation is governed by the characteristics of the overcurrent relay. There are two types of relays: instantaneous and time-delay. The time-current characteristic of an overcurrent relay can consist of two sections, the first one is independent of the current, the second one has an operating time that varies inversely with current. Depending on the rate with which the relay operating time and current are related, the time-overcurrent characteristic can be classified as inverse, very inverse and extremely inverse, see Figure 3.
The time-current characteristic can be represented by the following expression $[19,21]$ :

$$
t(I)=\frac{K}{\left(I / I_{a}\right)^{n}-1}
$$

where $n$ is a factor that characterizes each type of relay, $K$ is a factor to distinguish each member of a family, and $I_{a}$ is the pickup current; i.e., the smallest value of the current that will trigger the breaker to operate. Typical values of these parameters can be consulted in the literature for each type of characteristic [19, 21-23].

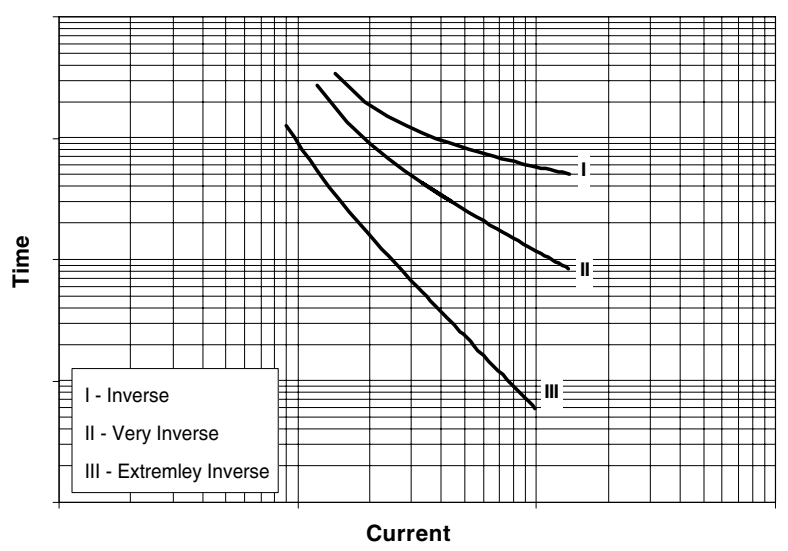

Figure 3. Time-current characteristics of overcurrent relays.

\section{Reclosers}

A recloser is an overcurrent protective device that can sense and interrupt fault currents as well as reclose automatically a predefined number of times a feeder. Its operation is similar to that of a breaker with a reclosing relay. In general, reclosers have less interrupting capability and cost less than breakers [1-3].

Recloser operation uses two time-current curves, see Figure 4. The first one, known as fast or instantaneous, is mainly used to save lateral fuses under temporary fault conditions. The second curve is known as slow or time-delay, and its main purpose is to delay recloser tripping, and allow fuses to blow under permanent fault conditions.

A recloser can be set for a number of different operations, although a very common reclosing sequence has two fast operations followed by two time-delay trips. 


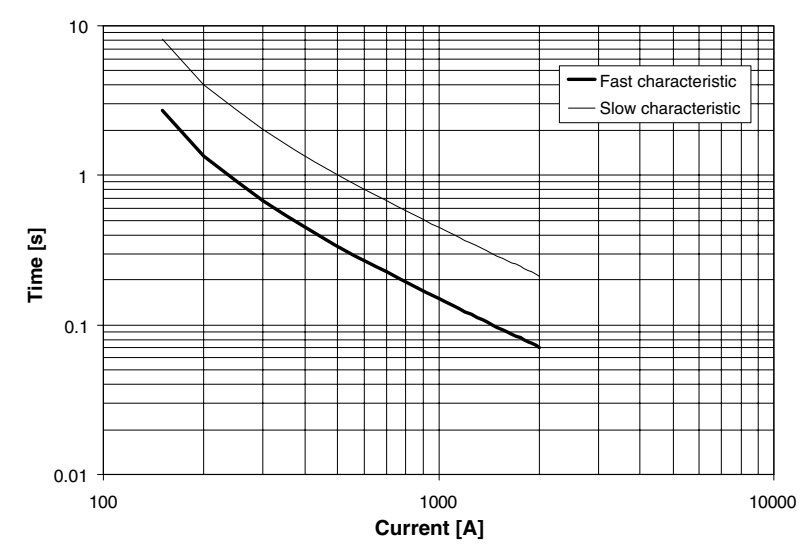

Figure 4. Recloser tripping characteristics.

\section{Fuses}

Several types of fuses are presently available in the market to protect distribution networks. In this work only current limiting and expulsion fuses have been modeled. Fuses of the first group limit the magnitude as well as the duration of the current; the second group limits only the duration of the fault, allowing the flow of overcurrents, which will be interrupted after one zero pass. These differences can significantly affect power quality.

A fuse model, irrespectively of the group to be represented, has to duplicate the following stages [18]: current sensing, arc initiation, arc interruption, current interruption. The melting period, during which temperature rises, begins with the fault and finishes when the fuse melts; during this stage the current flows without limitation. The melting mechanism of a fuse depends on the magnitude and the duration of the current, as well as on the electrical properties of the fuse. This characteristic is shown in the so-called time-current curve provided by manufacturers. The performance of a fuse is depicted by means of the minimum melting and the total clearing curves: a fuse has an arcing time, which is the time needed to interrupt the current after the fuse melts, so the total clearing time curve is deduced by adding the arcing time to the melting time, see Figure 5.

Figure 6 shows the operation of a current limiting fuse, from the instant at which the fault is caused until the instant at which the fuse melts and the current is interrupted. The operating time of a current limiting fuse can be shorter than half a cycle; however, this high speed has a cost, since an overvoltage is usually obtained. The fuse limits the let-thru energy to a fraction of the energy available from the system. The performance of a current limiting fuse can be deduced from the let-thru charts, which are very useful to obtain the current during a fuse operation.
An expulsion fuse interrupts a fault current at current zero; a current limiting fuse interrupts a fault current by forcing a current zero. Upon interruption, the operation of a current limiting fuse results in the insertion of additional impedance and the development of an arc voltage; when this voltage exceeds the system voltage, the arc is extinguished and the action is accomplished [18]. An expulsion fuse heats to its melting point when the fault occurs; the current continues to flow in the form of an arc, at zero current the arc is extinguished, being the fuse subjected to a transient recovery voltage (TRV), whose frequency and magnitude depend on the operating conditions [24]. One or several arc reignitions can be caused by the TRV; the process stops only when the dielectric strength build up is faster than that caused by the TRV.

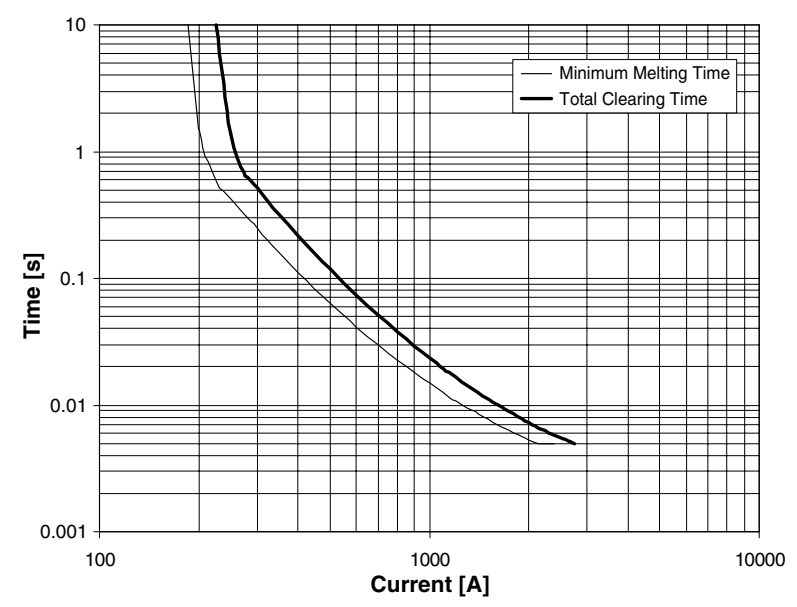

Figure 5. Extreme time-current characteristics of a fuse.

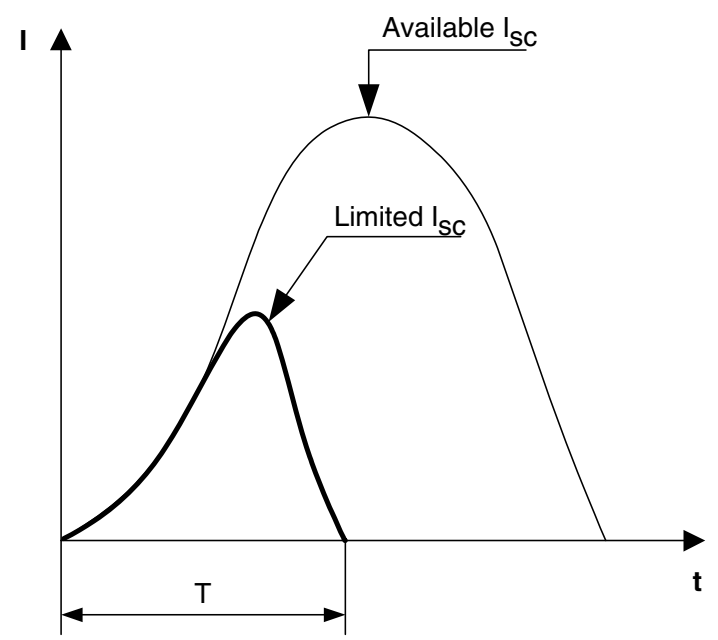

Figure 6. Effect of a current limiting fuse. 


\section{Sectionalizers}

A sectionalizer is an automatic circuit opening device. After a circuit has been deenergized by a backup protective device -such as a recloser or a reclosing breaker- a sectionalizer isolates the faulted portion of a distribution network $[2,3]$. After the fault has been isolated, the rest of the circuit is returned to service upon reclosure of the backup device. A sectionalizer has no capacity to break fault current, and it is usually installed downstream a breaker or a recloser. Sectionalizers are, therefore, used together with devices that have fault current breaking capacity.

A sectionalizer counts the interruptions of the backup device; it can be set to open after one, two, or three counts have been registered within a predetermined time span, see Figure 7. A sectionalizer opens during the open interval of the backup device. Although it cannot interrupt faults, it can be closed into them. Its operating mechanism is reset with temporary faults. Sectionalizers are built in single- and three-phase arrangements with hydraulic or electronic mechanisms.

Sectionalizers can be used in place of fuses or between a reclosing device and a fuse. They only detect current interruptions above a predetermined level and have no time-current characteristics, permitting easy coordination with other protective devices on the system. They provide additional protection without adding a coordination step to the protective scheme. Their advantages over fuse cutouts are many: they offer safety and do not open accidentally under load; after a permanent fault, the fault-closing capability of the sectionalizer greatly simplifies circuit testing; if a fault is still present, interruption takes place safely at the backup recloser; replacement of fuse links is not required; the possibility of error in the selection of the correct fuse link size and type is eliminated.

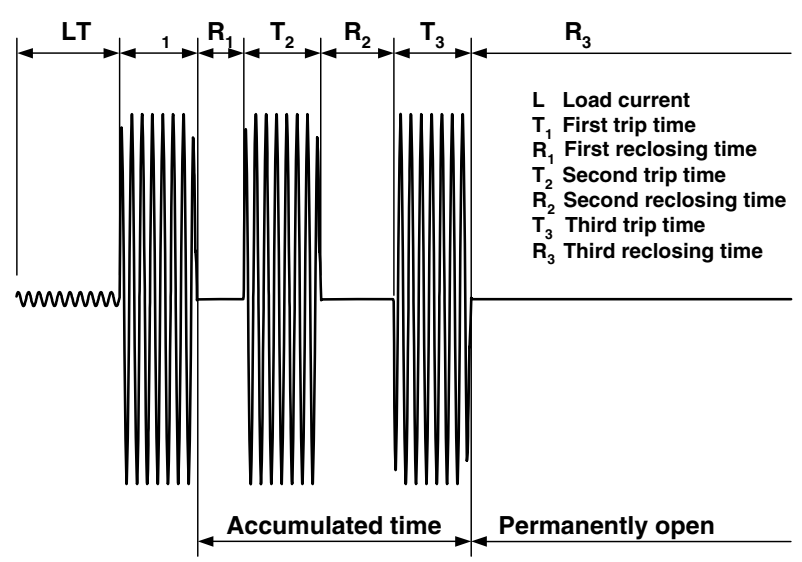

Figure 7. Sectionalizer performance.

\section{PROTECTION OF DISTRIBUTED GENERATORS}

\section{Interconnection Functions and Transformer Connections}

The functions of the interconnection protection depend on factors such as generator size, point of interconnection, type of generator and interconnection transformer connection. This section discusses the objectives of the intertie protection and how they can be achieved. As mentioned above, an important factor for the design of the intertie protection is the winding connection of the interconnection transformer. This aspect plays an important role in how DG units will interact with the utility system under faulted conditions. All connections have advantages and disadvantages which need to be addressed by the utility in their interconnection guidelines, since the choice of a transformer connection has a deep impact on interconnection protection requirements [10-12].

Although several transformer connections are widely used to interconnect dispersed generators to distribution systems, they can be classified into two groups, depending on the primary winding grounding.

- Ungrounded primary transformer winding: The major concern with an interconnection transformer with an ungrounded primary winding is that after the substation breaker is tripped for a permanent ground fault, the system is ungrounded. This subjects line-to-neutral equipment on the unfaulted phases to an overvoltage that will approach line-to-line voltage. This occurs if the DG is near the capacity of the load on the feeder when the substation breaker trips. Many utilities use ungrounded interconnection transformers only if an overload (200\% or more) on the DG occurs when the breaker trips. During ground faults, this overload level will not allow the voltage on the unfaulted phases to rise higher than the normal line-to-neutral voltage. For this reason, ungrounded primary windings should generally be reserved for smaller DGs where high overloads are expected on islanding.

- Grounded primary transformer winding: The major disadvantage with this connection is that it provides an unwanted ground fault current for supply circuit faults and reduces the current from substation breaker at the utility substation, which can result in a loss of relay coordination. When the DG is off-line (i.e., the generator breaker is open), the ground fault current will still be provided to the utility system if the dispersed generator interconnect transformer remains connected. This would be the case when interconnect protection trips the generator breaker. The transformer at the DG 
site acts as a grounding transformer with zero-sequence current circulating in the delta secondary windings. An interconnection transformer with grounded both primary and secondary windings also provides a source of unwanted ground current for utility feeder faults similar to that described above, as it also allows ground relays at the substation to respond to ground faults on the secondary of the DG transformer. This can require the utility to increase ground relay pickup and/or delay tripping to provide coordination, which reduces the sensitivity and speed of operation for feeder faults and can increase wire damage.

\section{Interconnection Protection}

Table I lists specific objectives of an interconnection protection system, as well as the relay requirements to accomplish each objective $[10,25]$.

Table I. Interconnection protection objectives.

\begin{tabular}{|l|l|}
\hline Objective & Protection Function \\
\hline $\begin{array}{l}\text { Detection of loss of } \\
\text { parallel operation }\end{array}$ & $81 \mathrm{O} / \mathrm{U}, 27,59,59 \mathrm{I}$ \\
\hline Fault backfeed detection & $\begin{array}{l}\text { Phase faults: 51V, 67, 21 } \\
\text { Ground faults: 51N, 67N, 59N, 27N }\end{array}$ \\
\hline $\begin{array}{l}\text { Detection of damaging } \\
\text { system conditions }\end{array}$ & $\begin{array}{l}\text { Negative sequence: 46, 47 } \\
\text { Loss of synchronism: 27 }\end{array}$ \\
\hline $\begin{array}{l}\text { Abnormal power flow } \\
\text { detection }\end{array}$ & 32 \\
\hline Restoration & 25 \\
\hline
\end{tabular}

Detection of Loss of Parallel Operation with the Utility System: The most basic means of detecting loss of parallel operation with the utility is to establish an over/ underfrequency (81O/U) and over/undervoltage (59/27) window within which the DG is allowed to operate. When the DG is islanded from the utility system due an abnormal condition, the frequency and voltage will move outside the operating window if there is a significant difference between load and generation levels. However, if the load and generation are near a balance at the time of separation, voltage and frequency may stay within the normal operating window and under/overfrequency and under/overvoltage tripping may not take place; in such case a transfer trip using a reliable means of communication may be necessary. The DG unit must be separated from the utility system quickly enough to allow the utility breaker at the substation to automatically reclose.

Fault Backfeed Detection: Small synchronous machines are typically so overloaded after the utility substation breaker trips that their fault current contribution is very small. The larger the synchronous DG, the greater is the chance that it will contribute significant current to a utility system fault. For this situation, fault backfeed detection should be provided. However, the level of fault current at various intervals after the fault occurs depends on the generator reactances and the decay rate depends on the generator terminal voltage during the fault and the field time constants. The decay of current for external faults needs to be addressed when choosing backfeed protection. Relay functions such as the 67,21 or $51 \mathrm{~V}$ can be used to provide phase fault backfeed detection. The pickup of 67 and 21 relays must be set above the level of current being supplied by the DG to the utility system. Ground fault backfeed removal depends also on the primary winding connection of the interconnection transformer. For grounded primary transformer windings, a $51 \mathrm{~N}$ neutral overcurrent relay or, in some cases, a $67 \mathrm{~N}$ ground direction relay is used. For ungrounded interconnection transformers, neutral overvoltage relays $(59 \mathrm{~N}, 27 \mathrm{~N})$ provide the detection for supply ground faults.

Detection of Damaging System Conditions: Unbalanced current conditions and the operation of single-phase protection devices, such as fuses and reclosers, on the utility distribution system can subject the DG unit to a high level of negative sequence currents, which may result in rapid rotor heating, causing generator damage. Many utilities provide the protection against these unbalanced currents using a negative sequence overcurrent relay (46). To provide protection for phase reversals after power restoration, a negative sequence voltage relay (47) can be also used. Another damaging condition that can be imposed on synchronous generators is loss of synchronism due to prolonged exposure to a slow-clearing utility system fault, which can result in shaft torque damage. The generator power can be suddenly reduced due to a short circuit while the mechanical power remains unchanged. During the time the generator is being driven out of synchronism, it experiences a severe voltage sag. The larger the voltage sag, the less real electrical power the generator can supply and the more unbalance there is between electrical and mechanical power causing the generator to rapidly accelerate, which in turn causes loss of synchronism. If the undervoltage relay (27) time delay is set too long, the generator can slip a pole with resulting damaging shaft torque. An impedance-based out-of-step relay can be used to detect this condition and separate the DG unit.

Abnormal Power Flow: Some interconnection contracts between co-generating DGs and utilities prohibit the small generator from providing power to the grid. The co-generating DG provides power solely to the local load at the DG facility, and reduces utility demand charges by "peak shaving". Utilities often install a directional power relay (32) to trip the DG unit if power inadvertently flows into the utility system for a predeter-mined time in violation of the interconnection contract. 
DG Tripping and Restoration Practices: Once the DG has been separated from the utility system, the intertie must be restored. Practices used within the industry depend on whether the DG facility matches or does not match the local load. In both cases, generators are automatically resynchronized, and in both cases utilities may use a synchrocheck relay (25) at the main incoming breaker.

\section{EMTP MODELS}

This section details the main characteristics of the models implemented in ATP for representation of distribution feeder and interconnection DG protective devices. The first subsection includes those devices installed in distribution feeders and tapped lines [22, 23], while the second one summarizes models for protective relays needed to accomplish the objectives and functions shown in Table I [25].

\section{Distribution Feeder Protective Devices}

Circuit Breakers - Overcurrent Relays: The developed models are adequate for power quality studies and have some significant limitations. The circuit breaker model does not include dynamic arc representation and by default all opening operations are successful; i.e. no reignitions and dielectric breakdowns can be duplicated by means of simulations. The breaker module is based on a TACScontrolled switch [14]; that is, controlled by a overcurrent relay whose time-current curve parameters can be easily specified by users, see equation (1). In addition, it includes a snubber circuit in parallel to the switch, being the values of the snubber parameters internally calculated from the time-step size and the rated voltage of the system. Figure 8 shows the performance of the circuit breaker model during a three-phase fault. Note that two different time-current curves of the overcurrent relay were selected.

Reclosers: The recloser model is also based on a TACScontrolled switch. It allows users to include two tripping curves (fast and slow), select the type of time-current characteristic (inverse, very inverse, extremely inverse), and specify the number of reclosing operations for each characteristic, as well as the duration of each reclosing interval. Figure 9 shows one case in which the fault condition remains after two reclosing operations, and the contacts remain open after the third opening action. Note that only the fast characteristic is used in the three operations, but the opening periods are different.

Fuses: Although minimum melting curves are similar for both types of fuses, the approach chosen for representing every type has been different. Since the action of a current limiting fuse results in the sudden insertion of a high value resistance, this type of fuse has been modeled as a variable resistance controlled from a TACS section, in which users can specify the parameters that govern the fuse resistance [23]. The input of the minimum melting time-current curve is made by means of a regression equation that matches the characteristic provided by the manufacturer. This means that different equation coefficients have to be considered for each manufacturer.

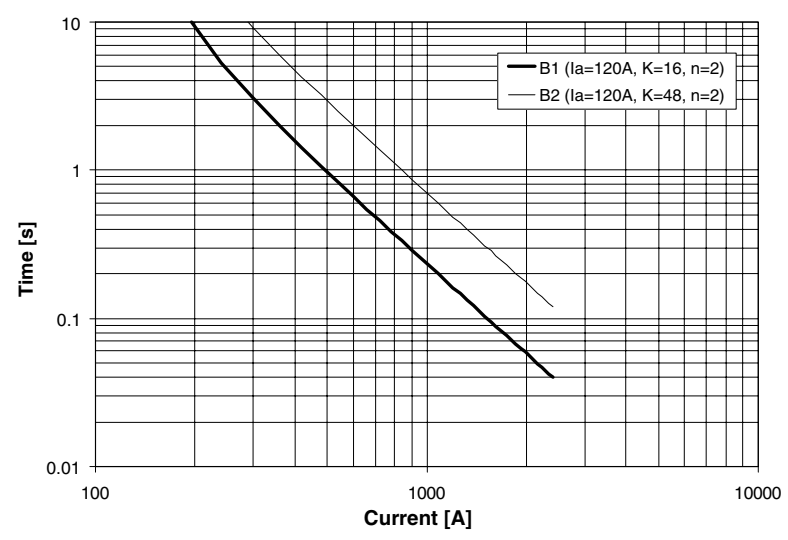

a) Time-current characteristics.

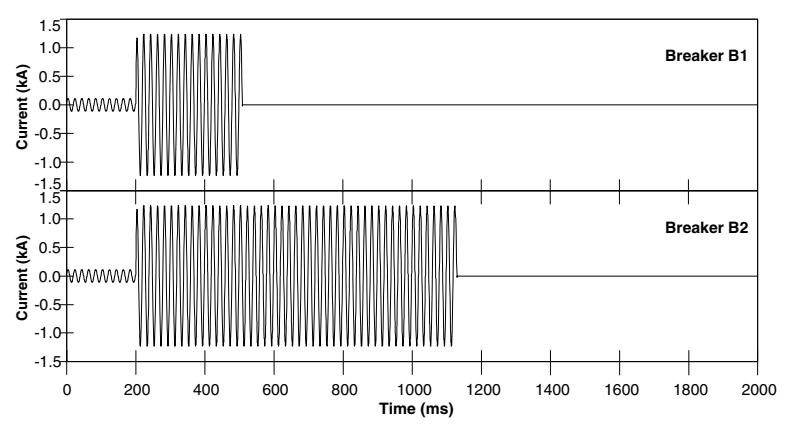

b) Circuit breaker currents.

Figure 8. Circuit breaker operation. Three-phase fault.

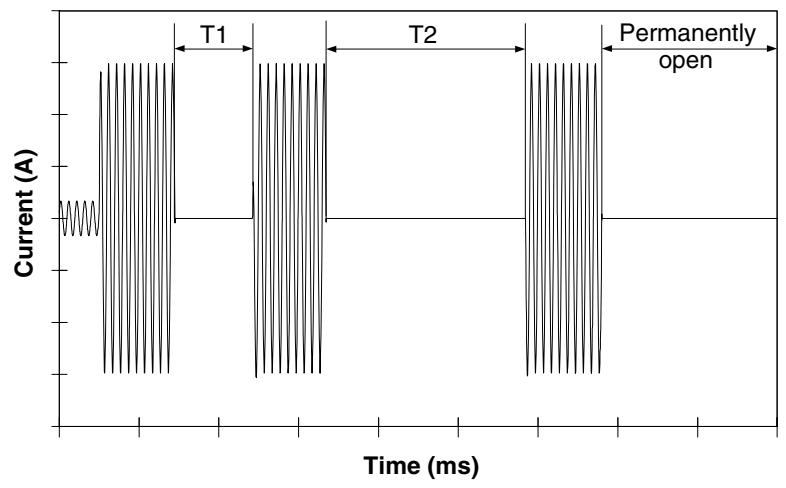

Figure 9. Recloser performance.

An expulsion fuse can be represented as a switch that opens at the first zero-current. Therefore, these fuses have been modeled as TACS-controlled switches. The 
module required for this type of fuses is basically the same developed for representation of current limiting fuses, but without including any post-melting resistance. For more details on modeling of both types of fuses see references [22-24, 26, 27].

Figure 10 shows the operation of both types of fuses. The plots depict the voltage and the current through each type of fuse. One can observe that the overvoltage caused by the operation of the current limiting fuse is larger than that caused by the expulsion fuse, while the total clearing time is longer for the expulsion type.

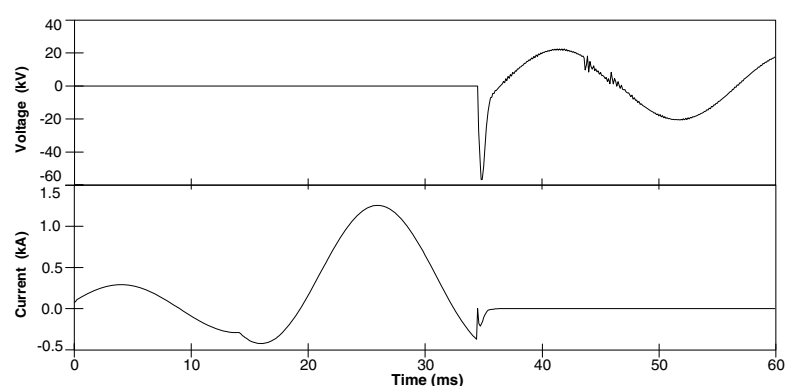

a) Current limiting fuse.

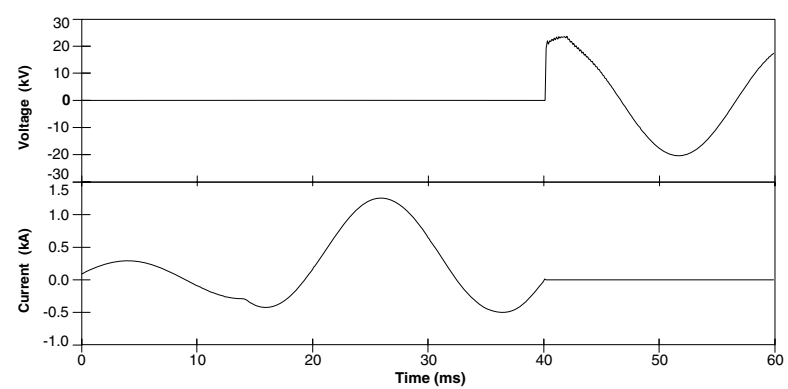

b) Expulsion fuse.

Figure 10. Fuse operation.

The temperature of a fuse increases toward its melting value during a fault. When coordinated with a recloser, the time-current characteristic of a fuse is affected by the heating-cooling cycle: if the recloser operates faster than the fuse, this will heat during the fault and cool during the reclosing time interval, see Figure 11. An adjustment of the fuse time-current characteristic is therefore needed. A more advanced model have been also implemented to account for the thermal response of a fuse during multiple reclosing operations using the coordination principles between fuses and reclosers presented in [28]. The features of this fuse model are detailed in reference [23].

Sectionalizers: As for other circuit interrupters, the sectionalizer model is based on a TACS-controlled switch with a parallel snubber circuit, whose parameters are internally estimated from the time-step size and the distribution system rated voltage. The user has to specify the number of interruptions of the backup device and the minimum time during which the current is interrupted in each operation. The sectionalizer opens the circuit after the specified number of interruptions has been registered. Figure 12 shows a case in which the sectionalizer opens after detecting the third interruption. Note that the recloser recovers the current of those loads that are not in the path of the fault location situated downstream the sectionalizer.

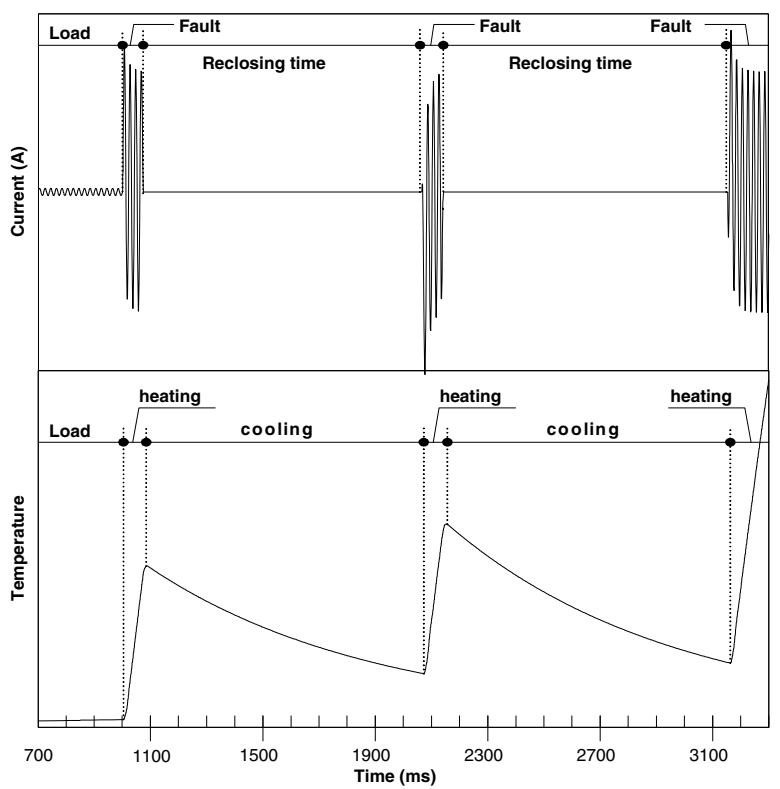

Figure 11. Heating and cooling of a fuse.

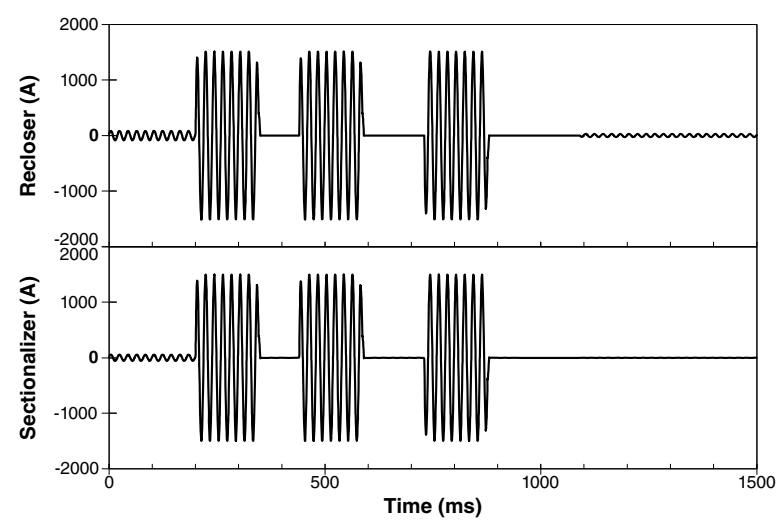

Figure 12. Sectionalizer operation.

\section{Interconnection DG Protection}

It is based on the previous circuit breaker model and a library of relay modules whose development and implementation were similar to those of the overcurrent 
relay model summarized above. As an example, Figure 13 shows the characteristics that can be represented with over/undervoltage relays.

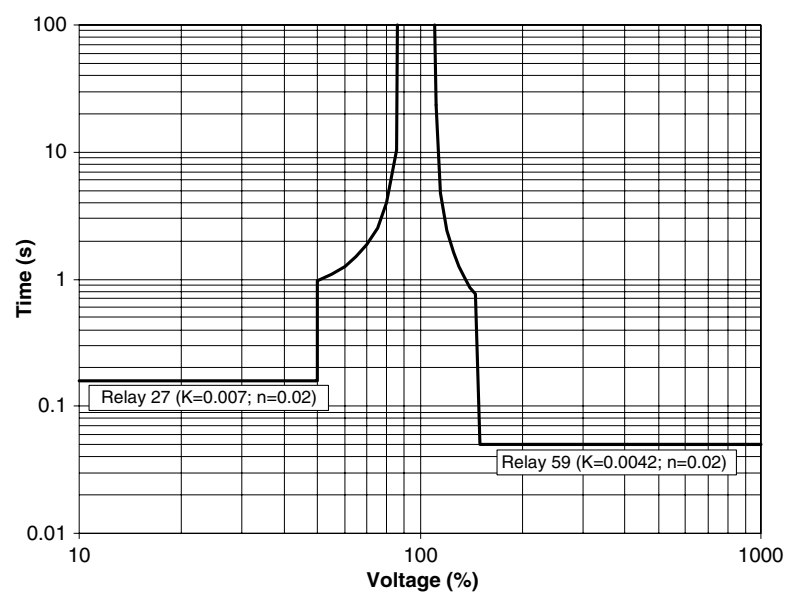

Figure 13. Over/undervoltage relay characteristics.

Table II lists the developed models [25]. They have been classified into two groups, models for distribution feeder protection and models for DG interconnection protection.

Table II. Protective devices implemented in ATP.

\begin{tabular}{|l|l|}
\hline Function & Protective devices \\
\hline \multirow{5}{*}{ Feeder protection } & $\begin{array}{l}\text { Circuit breaker } \\
\text { Overcurrent relay 51 } \\
\text { Recloser } \\
\text { Expulsion fuse } \\
\text { Current limiting fuse } \\
\text { Sectionalizer }\end{array}$ \\
\hline \multirow{5}{*}{$\begin{array}{l}\text { Relay function 27 } \\
\text { protection }\end{array}$} & Relay function 32 \\
& Relay function 46 \\
& Relay function 47 \\
& Relay function 51 \\
& Relay function 51N \\
& Relay function 59 \\
& Relay function 59N \\
& Relay function 81U \\
& Relay function 81O \\
\hline
\end{tabular}

\section{TEST STUDIES}

\section{Test system}

Figure 14 shows the configuration of the system analyzed in this work and the parameters of some components. The lower voltage side of the substation transformer is grounded by means of a zig-zag reactor of $75 \Omega$ per phase.
The diagram depicts the location of some faults that will be used to analyze the performance of the protective device models and the coordination between them. The case studies analyzed in this work correspond to the following scenarios [25, 29]:

- Example 1: There is a fault at node A, which is sensed by overcurrent relays at B1 and B2. Due to time-current characteristics of the relays, breaker B2 opens first. The case study analyzes the perfor mance of the relay models and discusses some solutions for this case.

- Example 2: As a consequence of the operation of breaker B2 (e.g., a miscoordination as in the previous example), G2 passes to operate in islanding mode. This is not allowed in the interconnection contract with the utility, so the loss of parallel operation must be detected and the generator must be disconnected.

- Example 3: There is a fault at node B, which is sensed by the fuse F1 and the recloser R1. Since fuse saving is implemented, R1 must open first. So, even if the fault is permanent, fuse F1 should not open before one or several reclosing operations of R1. However, the presence of generator G1 may cause miscoordination between R1 and F1, and consequently F1 will open first. A solution is proposed by installing a sectionalizer instead of fuse F1.

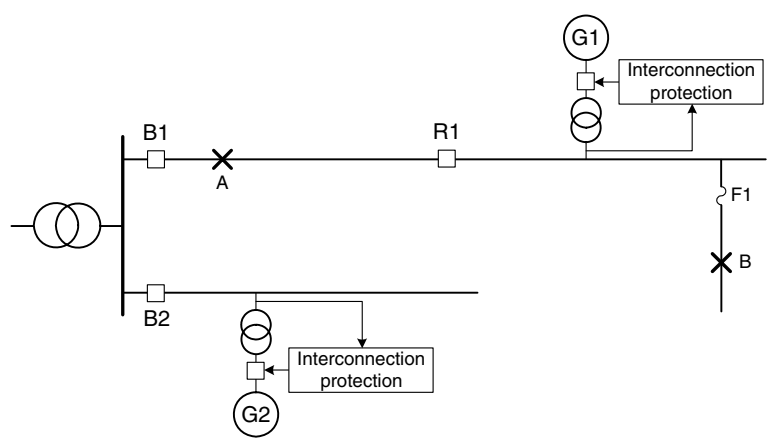

HV equivalent: $110 \mathrm{kV}, 1500 \mathrm{MVA}, \mathrm{X} / \mathrm{R}=10$ Substation transformer: $110 / 25 \mathrm{kV}, 8 \mathrm{MVA}, 8 \%$, Yd

Lines: $\mathrm{Z}_{1 / 2}=0.61+\mathrm{j} 1.24, \mathrm{Z}_{0}=0.76+\mathrm{j} 4.96 \Omega / \mathrm{km}$

Figure 14. Test system.

All the examples are based on a system with the configuration shown in Figure 14, but the operating conditions and device settings are different for each study.

The goal of the test cases analyzed in this work is twofold:

1. To illustrate how the presence of small generation units embedded into the distribution grid can alter 
the coordination between protective devices and lead to their misoperation.

2. To analyze the response of relays installed for protection of DG interconnection.

The simulations have been carried out with several limitations that are listed below:

- The interconnect protection for DG units is always at the primary side of interconnection transformers.

- The representation of substation and distribution transformers, as well as interconnection transformers, is lineal; that is, saturation effects are not included in transformer models. This prevents from the simulation of some transients, such as transformer inrush.

- It is assumed that the input to relays is not modified/ altered by instrument transformers. Therefore, CT and VT models are not included in simulations and relay inputs are directly from phase currents and phase-to-ground voltages.

Finally, it is worth mentioning that only simulation results corresponding to three-phase faults are analyzed. For a simplified analysis of the impact that the connection of embedded generators can have on the coordination of distribution protective devices see reference [29].

\section{Example 1: Overcurrent relay miscoordination}

Figure 15 shows the characteristics of the overcurrent relays that control circuit breakers B1 and B2. Although the fault is on the upper feeder, the resulting current flow due to the presence of DG may result in an undesirable tripping of the unfaulted feeder breaker. Simulation results are depicted in Figure 16. The fault current flowing through the unfaulted feeder is much smaller than the fault current flowing through the breaker installed on the faulted feeder, but for a fault at node A circuit breaker B2 opens first. However, after reclosing both B1 and B2, B1 opens faster and B2 remains closed. Note that although B2 recloses first and, although the fault is isolated because B1 is still opened, the current through B2 is very high; this is due to the opposite phase between both sides of B2 at the time it recloses. It is also worth mentioning that at the time $\mathrm{B} 2$ recloses, the generation unit should have been disconnected from the feeder, see the two following examples.

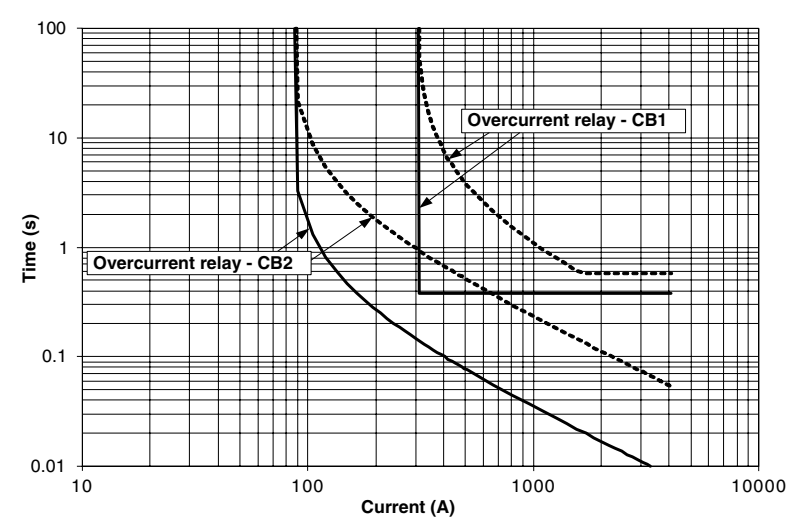

Figure 15. Example 1: Time-current characteristics of overcurrent relays.

Note the different shapes of the overcurrent sensed by each circuit breaker; the current through B2 exhibits the typical waveshape of the short-circuit current caused by a fault not far from a synchronous generator.

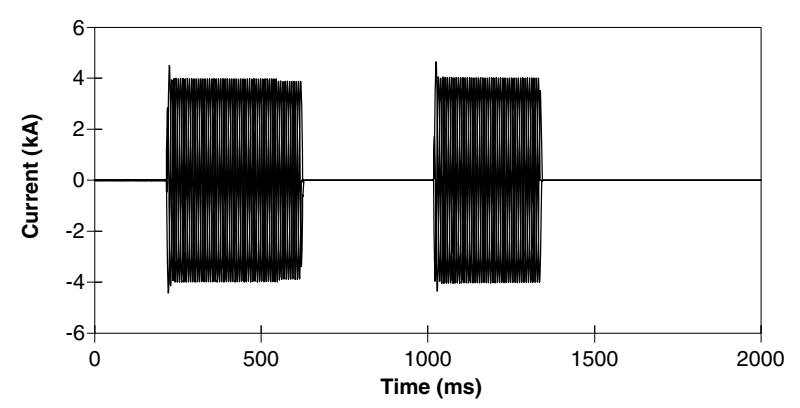

a) Faulted feeder - Current through circuit breaker B1.

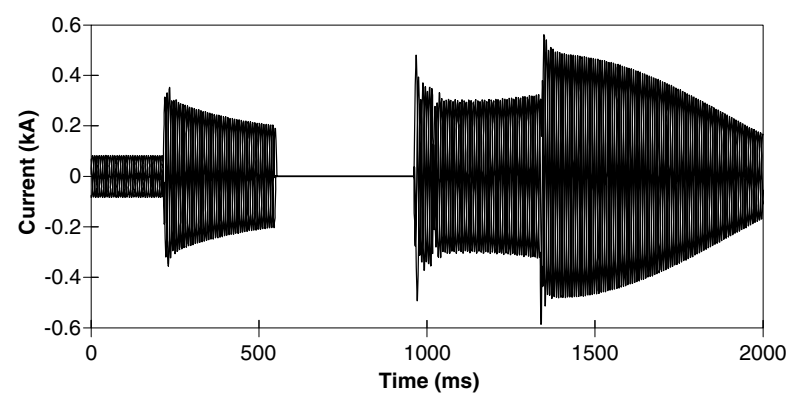

b) Unfaulted feeder - Current through circuit breaker B2.

Figure 16. Example 1: Simulation results.

Several solutions have been proposed for this case, see for instance [25] and [29]. Since this can be seen as a miscoordination between overcurrent relays, one solution is to select faster time-current characteristics for the overcurrent relay of the faulted feeder, see Figure 17.

Figure 18 shows the new results with the new time-current curves. This solution should be chosen with caution since 
the new characteristic should be also coordinated with protective devices located downstream B1.

Other solution is to directionalize the overcurrent relays of substation breakers. This will avoid some future miscoordination with other protective devices.

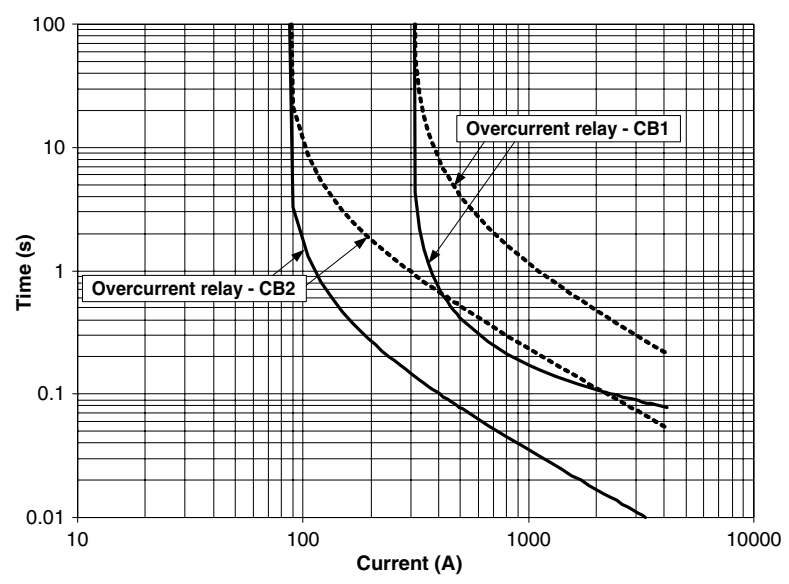

Figure 17. Example 1: New relay characteristics.

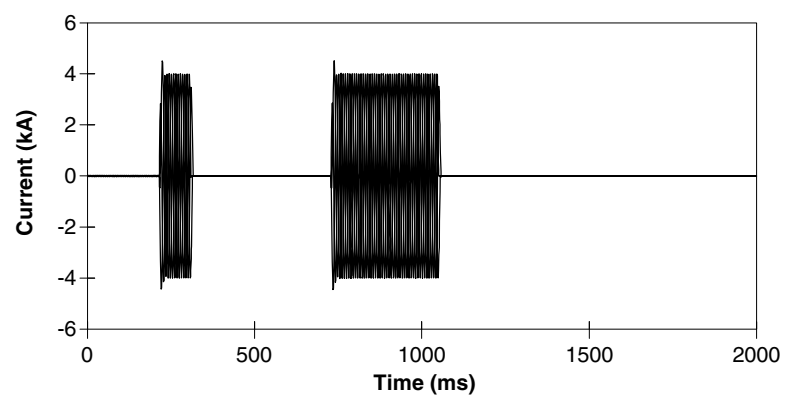

a) Faulted feeder - Current through circuit breaker B1.

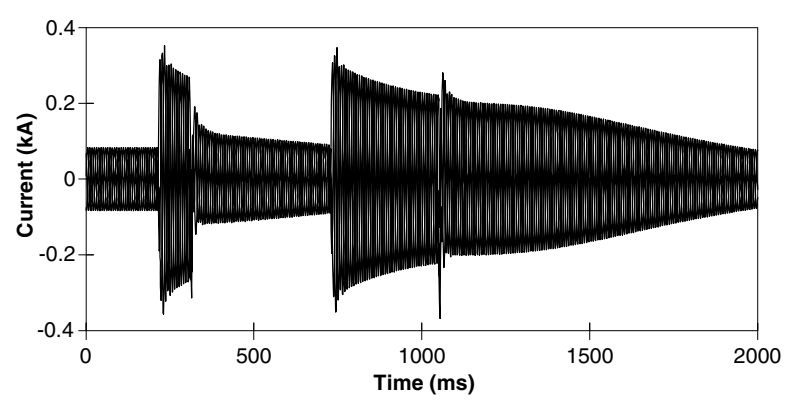

b) Unfaulted feeder - Current through circuit breaker B2.

Figure 18. Example 1: Simulation results with new relays.

\section{Example 2: Detection of loss of parallel}

The previous example has presented one case in which the miscoordination between protective relays may create a generation island: after breaker B2 opens the bottom generation unit is separated from the feeder if the breakerrelay set does not reclose. Several options for detecting the loss of parallel and separate the generation unit from the utility system may be used.

Assume that breaker B2 opens and the feeder demand exceeds the rated power of the generator G2. The unbalance between load and generation can be detected in several ways. Figure 19 shows how the current supplied by the generator increased after breaker B2 opens. If the control of the prime mover is disabled, the overcurrent protection will be able to separate the unit from the feeder after more than 4 seconds.

As mentioned above, detecting the island mode can be also based on measuring the voltage and the frequency at the generator terminals. Unless the exciter control was disabled, a similar performance to that shown in Figure 19 could be expected from sensing the voltage. A more reasonable means could be based on measuring the frequency.

Figure 20 shows the characteristics of the over- and under-frequency relays tested for this case. The frequency measured after breaker B2 opens is shown in Figure 21. As expected, the generator frequency decreases and the relay sends its signal after the frequency value is below $99 \%$ of the rated value $(50 \mathrm{~Hz}$ in this example). Taking into account the operating conditions and the generator parameters (e.g., rotor inertia), the separation takes place more than 3.5 seconds after the opening of breaker B2.

The results from this study can be useful for adjusting the different protective relays and devices involved in the test system. For instance, it is obvious from the above results that the reclosing of breaker B2 should not be made in less than 3.5 seconds; if this period is too long, then the frequency relays must be readjusted.

More sophisticated anti-islanding algorithms have been proposed during the last years [30-32].

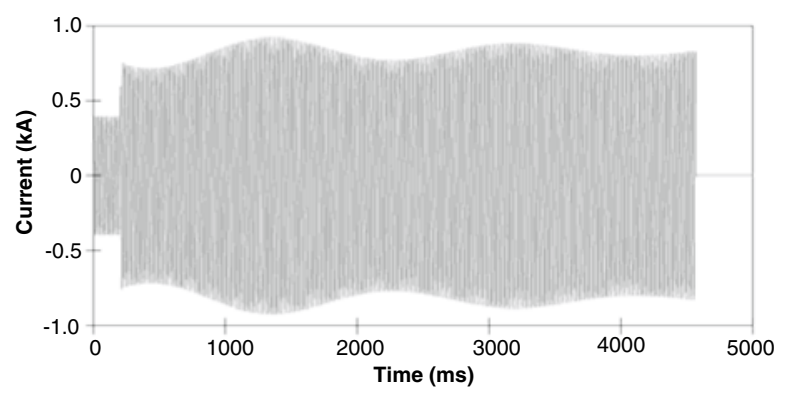

Figure 19. Example 2: Transient current at the interconnection. 


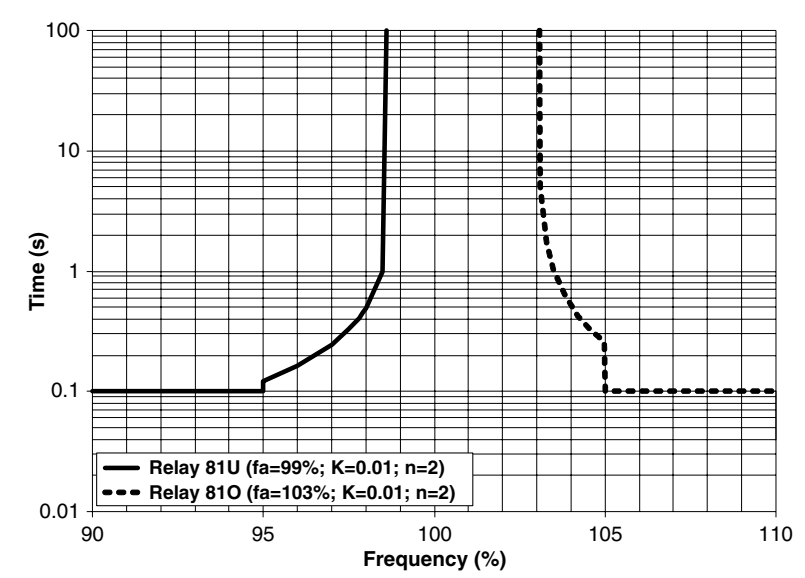

Figure 20. Example 2: Over/underfrequency relay characteristics for $\mathrm{G} 2$.

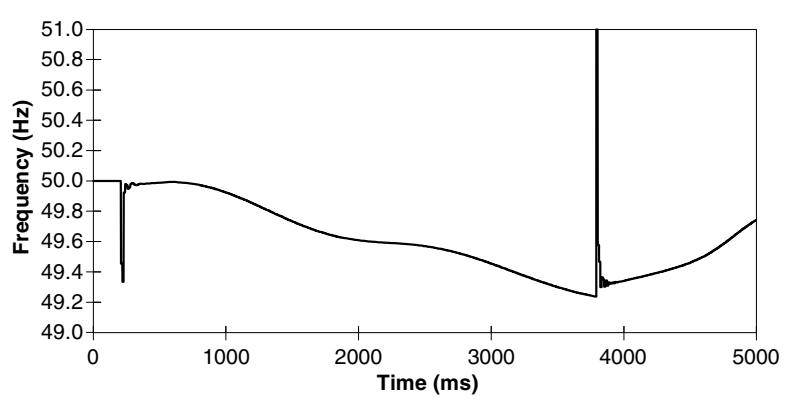

Figure 21. Example 2: Simulation results with frequency relays.

\section{Example 3: Miscoordination between protective devices}

The first example presented a case in which miscoordination between overcurrent relays that control circuit breakers may occur. The present example details a case in which a miscoordination between a recloser and a fuse may be caused by the presence of an embedded generator.

Since most faults in overhead distribution networks are temporary, utilities use fuse saving to prevent unnecessary lateral fuse operations. This practice is implemented with an instantaneous relay on a breaker or the fast curve on a recloser.

Assume that there is a temporary fault on the node B, see Figure 14, and the fault current is sensed by the fuse F1 and the recloser R1. Figure 22 shows the fast and the slow characteristics of the recloser R1, the characteristic of the fuse F1, for which the minimum melting time curve is used, as well as the fault current value sensed by both devices. If no generator is connected to the network, the fault current through both devices is basically the same.
The sequence of operations implemented in this example under such conditions will be as follows: (i) the recloser operates with its fast curve and opens first; (ii) the recloser closes the circuit after the selected reclosing time; (iii) if the fault is gone, no other action is necessary; otherwise, the operation is repeated. However, this time the slow characteristic of the recloser is used and then (according to Figure 22) the fuse opens. Figure 23 shows the results obtained with this case when there is not distributed generation.

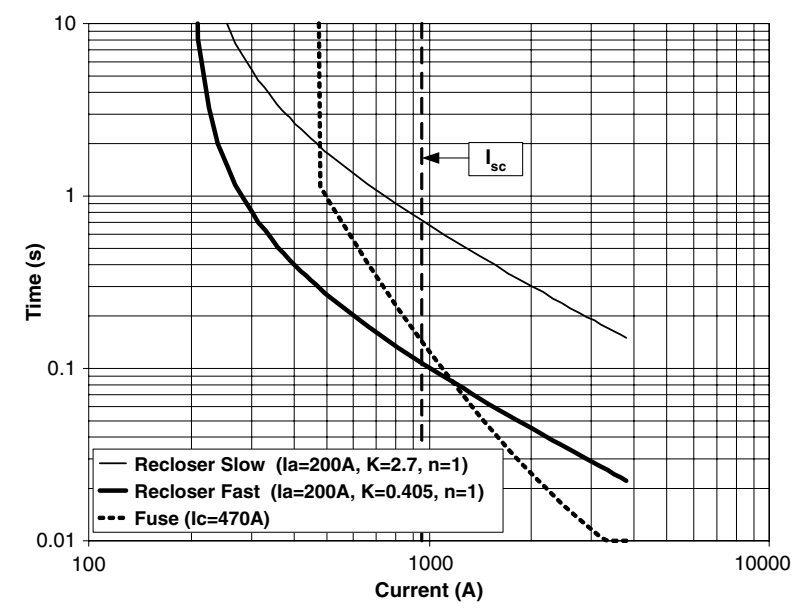

Figure 22. Example 3: Time-current characteristics of the recloser and the fuse.

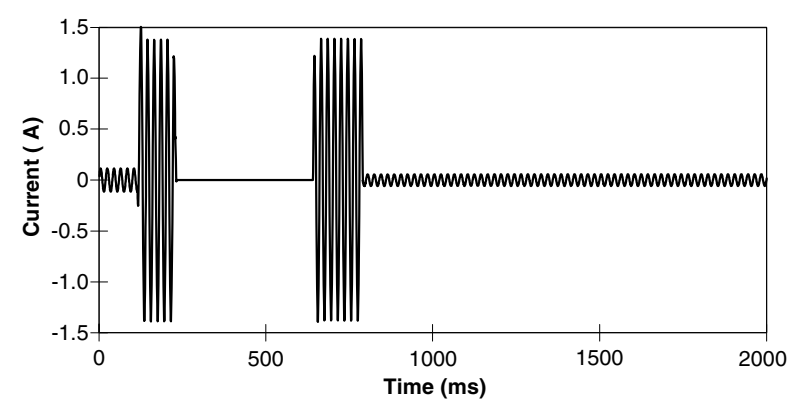

a) Current through the recloser R1.

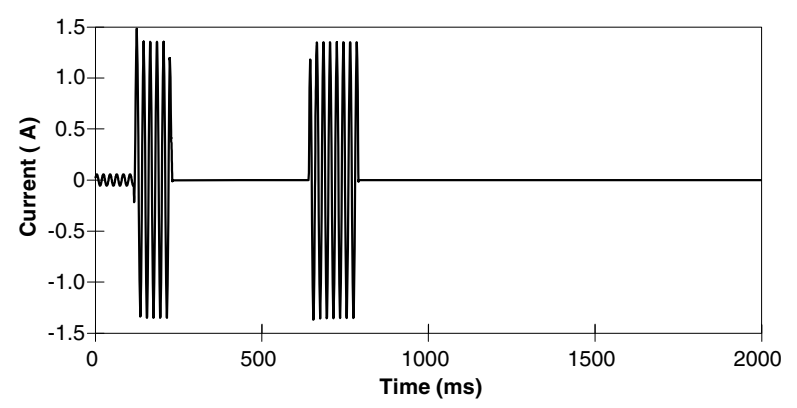

b) Current through the fuse F1.

Figure 23. Example 3: Simulation results without distributed generation. 
When a generator is connected to the system and the point of common coupling is between the recloser and the fuse, as in Figure 14, the current through both devices in front of a fault located at point $B$ will be different, since the current through the recloser will decrease and the current through the fuse will increase with respect to the values without generation [29]. This may cause a miscoordination between both devices, and the fuse could open first, even if the fault is temporary. Figure 24 shows the new fault currents that result after connecting the generator. Note that the fuse opens first, so neither the recloser not the interconnection protection of the generator act in front of this fault. One can also deduce from the comparison of the plots of Figures 23 and 24 that, as expected, the fault current through R1 has decreased and the fault current through F1 has increased when the generator is connected.

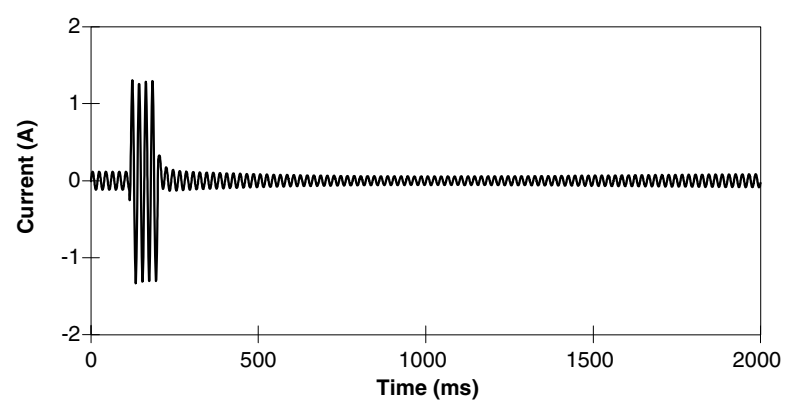

a) Current through the recloser $\mathrm{R} 1$.

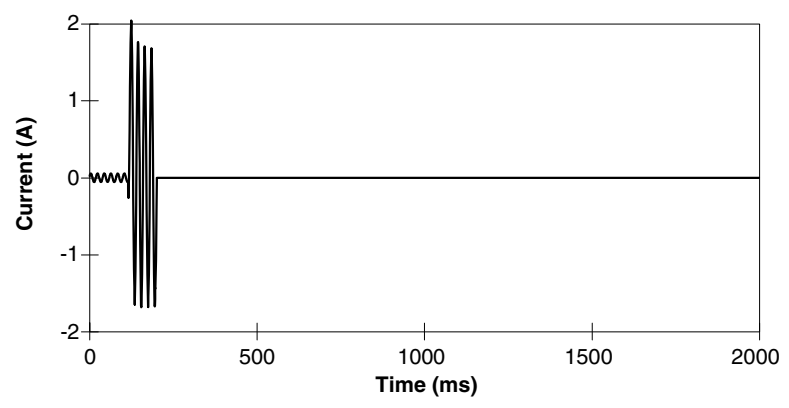

b) Current through the fuse F1.

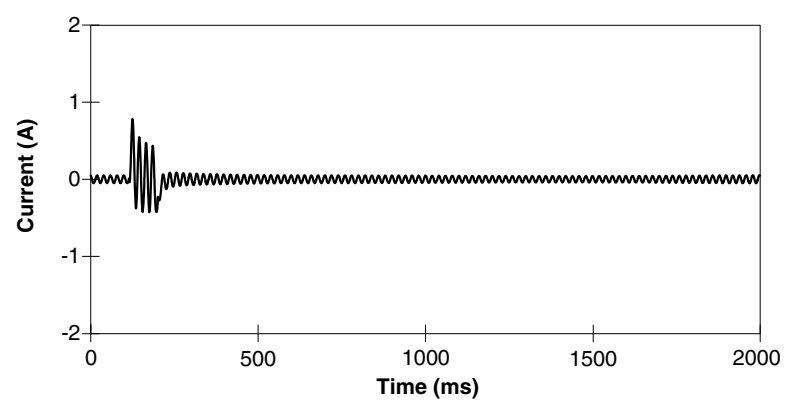

c) Current supplied by the generator G1.

Figure 24. Example 3: Simulation results with distributed generation.
This problem may be solved by replacing the fuse with a sectionalizer coordinated with the recloser. In this case the sectionalizer will open after the first reclosing and before the second operation of the recloser, as in the previous case, when fuse saving was working properly and the fuse did not open before the first reclosing operation. Figure 25 shows the simulation results when the sectionalizer is installed instead of the fuse F1. It is important to mention that in this case the interconnection protection of the generator decouples the machine from the network before the first reclosing operation, so when the first reclosing of R1 takes place the generator has been already decoupled from the feeder.

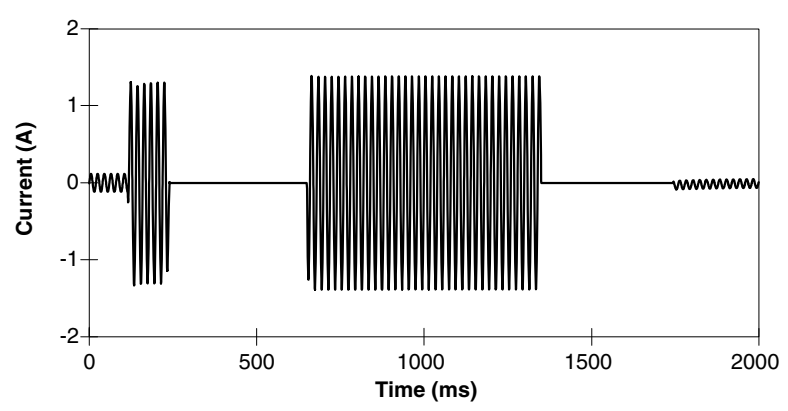

a) Current through the recloser $\mathrm{R} 1$.

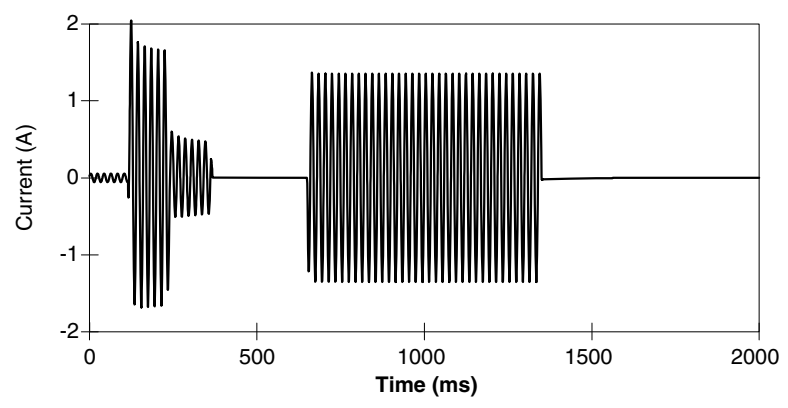

b) Current through the sectionalizer.

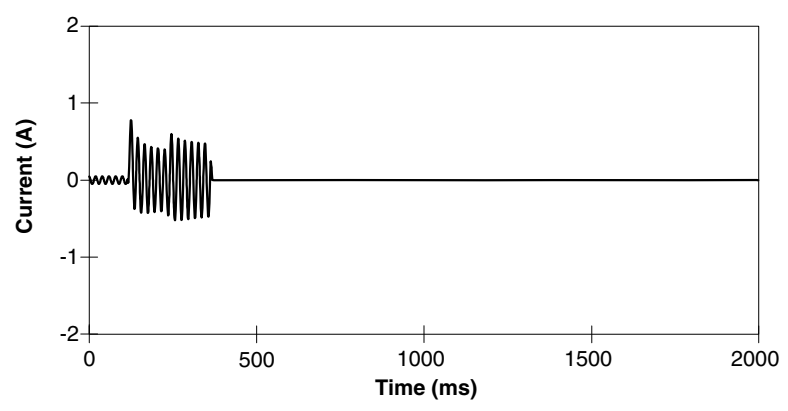

c) Current supplied by the generator G1.

Figure 25. Example 3: Simulation results with the sectionalizer. 


\section{CONCLUSIONS}

DG can have a positive impact on the performance of a distribution system; however, small embedded generation units alter the power flow direction and can lead to miscoordination of protective devices [8, 17], [29]. This paper has presented the main features of protective device models implemented in an EMTP-type tool to analyze the impact that small distributed generators embedded in a distribution utility grid can have on the performance of the protection system. Simulation results have shown that, under certain circumstances, a generation unit alters the coordination between feeder protective devices before it is separated from the grid, and can lead to miscoordination.

The study has been based on the presence of synchronous generators only, without considering other types of generating machines or any power electronics interface. Future work will consider the presence of other DG technologies (wind, photovoltaic, fuel cell), whose impact can be different from that obtained in this work, with special emphasis on electronic-interfaced DG.

\section{REFERENCES}

[1] T.A. Short. "Electric Power Distribution". CRC Press, $1^{\text {th }}$ Edition. September, 2003.

[2] J.M. Gers and J.E. Holmes. "Protection of Electricity Distribution Networks". IEE Power and Energy Series. $2^{\text {nd }}$ Edition. 2004.

[3] T. Gonen. "Electric Power Distribution System Engineering". CRC Press, $2^{\text {nd }}$ Edition. December, 2007.

[4] H. Lee Willis and W.G. Scott. "Distributed Power Generation. Planning and Evaluation". CRC Press, $1^{\text {th }}$ Edition. January, 2000.

[5] M. Godoy Simoes and F.A. Parrel "Renewable Energy Systems: Design and Analysis with Induction Generators". CRC Press, $1^{\text {th }}$ Edition. May, 2004.

[6] G.M. Masters. "Renewable and Efficient Electric Power Systems". Wiley-IEEE Press. August, 2004.

[7] R.A. Walling, R. Saint, R.C. Dugan, J. Burke and L.A. Kojovic. "Summary of distributed resources impact on power delivery systems". IEEE Trans. on Power Delivery. Vol. 23, Issue 3, pp. 1636-1644. July, 2008.

[8] IEEE Power System Relay Committee. "Impact of distributed resources on distribution relay protection". August, 2004.
[9] IEEE Std. 1547-2003. "IEEE Standard for Interconnecting Distributed Resources with Electric Power Systems". 2003.

[10] C.J. Mozina. "Distributed generator interconnect protection practices". IEEE Pes Transmission and Distribution Conference and Exhibition, pp. 1164-1170. May, 2006.

[11] C.J. Mozina. "Interconnect protection of dispersed generators". Transmission and Distribution Conference and Exposition, pp. 707-723. 2001.

[12] C.J. Mozina. "Interconnection protection of IPP generators at commercial/industrial facilities". IEEE Trans. on Industry Applications. Vol. 37, Issue 3, pp. 681-688. May/June, 2001.

[13] G. Dalke, A. Baum, B. Bailey, J.M. Daley, B. Duncan, J. Fischer, E. Hesla, R. Hoerauf, B. Hornbarger, W.-J. Lee, D.J. Love, D. McCullough, C. Mozina, N. Nichols, L. Padden, S. Patel, Al Pierce, P. Pillai, G. Poletto, R. Rifaat, M.K. Sanders, J.M. Shelton, T.N. Stringer, J. Weber, A. Wu and R. Young. "Application of islanding protection for industrial and commercial generators". 59 $9^{\text {th }}$ Annual Conf. for Protective Relay Eng. 2006.

[14] H.W. Dommel. "ElectroMagnetic Transients Program". Reference Manual (EMTP Theory Book). Bonneville Power Administration. Portland, USA. 1986.

[15] J. Mahseredjian, V. Dinavahi and J.A. Martinez. "Simulation tools for electromagnetic transients in power systems: Overview and challenges". IEEE Trans. on Power Delivery. Vol. 24, Issue 3, pp. 1657-1669. July, 2009.

[16] J.A. Martinez and J. Martin-Arnedo. "Expanding capabilities of EMTP-like tools: From analysis to design". IEEE Trans. on Power Delivery. Vol. 18, Issue 4, pp. 1569-1571. October, 2003.

[17] A. Girgis and S. Brahma. "Effect of distributed generation on protective device coordination in distribution system". Large Engineering Systems Conference on Power Engineering, pp. 115-119. 2001.

[18] IEEE Std C37.48.1-2002. "IEEE Guide for the Operation, Classification, Application and Coordination of Current-Limiting Fuses with rated Voltages 1-38 kV".

[19] IEEE Std C37.112-1996. "IEEE Standard InverseTime Characteristic Equations for Overcurrent Relays".

[20] J.A. Martinez-Velasco and M. Popov. "Circuit Breakers”. In: J.A. Martinez-Velasco (Ed.). Power System Transients: Parameter Determination. CRC Press. 2009. 
[21] IEEE Power Eng. Soc., Power Syst. Relaying Ctte., Computer Representation of Overcurrent Relay Characteristics Working Group. "Computer representation of Overcurrent relay characteristics". IEEE Trans. on Power Delivery. Vol. 4, Issue 3, pp. 1659-1667. July, 1989.

[22] J.A. Martinez and J. Martin-Arnedo. "Modeling of protective devices for voltage sag studies in distribution systems". IEEE Power Engineering Society General Meeting. June 6-10, 2004.

[23] J.A. Martinez and J. Martin-Arnedo. "Voltage sag studies in distribution networks. Part I: System modeling”. IEEE Trans. on Power Delivery. Vol. 21, Issue 3, pp. 1670-1678. July, 2006.

[24] K.L. Leix, L.A. Kojovic, M.B. Marz, and G.C. Lampley. "Applying current-limiting fuses to improve power quality and safety". IEEE Transmission and Distribution Conference. April, 1999.

[25] J.A. Martinez and J. Martin-Arnedo. "EMTP modeling of protective devices for distribution systems with distributed generation". IEEE Power Engineering Society General Meeting. July, 2010.

[26] L.A. Kojovic, S.P. Hassler, K.L. Leix, C.W. Williams and E.E. Baker. "Comparative analysis of expulsion and current-limiting fuse operation in distribution systems for improved power quality and protection". IEEE Trans. on Power Delivery. Vol. 13, Issue 3, pp. 863-869. July, 1998.

[27] L.A. Kojovic and S.P. Hassler. "Application of current limiting fuses in distribution systems for improved power quality and protection". IEEE Trans. on Power Delivery. Vol. 12, Issue 2, pp. 791800. April, 1997.

[28] C.J. Cook and D.A. Myers. "The use of coolingfactor curves for coordinating fuses and reclosers". IEEE Power Engineering Society General Meeting. June 6-10, 2004.

[29] J.A. Martinez and J. Martin-Arnedo. "Impact of distributed generation on distribution protection and power quality". IEEE Power Engineering Society General Meeting. July, 2009.

[30] K. El-Arroudi, G. Joos, I. Kamwa. and D.T. McGillis. "Intelligent-based approach to islanding detection in distributed generation". IEEE Trans. on Power Delivery. Vol. 22, Issue 2, pp. 828-835. April, 2007.

[31] T. Funabashi, K. Koyanagi and R. Yokoyama. "A review of islanding detection methods for distributed resources". IEEE Power Tech. Conference Proceedings. Bologna, Italy. June 23-26, 2003.

[32] C.M. Affonso, W. Freitas, W. Xu and L.C.P. da Silva. "Performance of ROCOF relays for embedded generation applications". IEE Proceedings Generation, Transmission \& Distribution. Vol. 152, Issue 1, pp. 109-114. January, 2005. 